\title{
Sistemas intercalares com abacaxizeiro como alternativa de renda durante a formação de cafezais irrigados
}

\author{
Vânia Aparecida Silva(1), Luiz Antonio Lima(2), Fabrício Teixeira Andrade ${ }^{(3)}$, Ester Alice Ferreira( ${ }^{(1)}$, \\ Evandro Andrade de Souza Júnior ${ }^{(1)}$, Matheus Figueiredo Braga Colares ${ }^{(2)}$ e Lais Lorena Queiroz Moreira( ${ }^{(4)}$
}

\begin{abstract}
(1)Empresa de Pesquisa Agropecuária de Minas Gerais, Unidade Regional do Sul de Minas, Campus da Universidade Federal de Lavras, s/no, Caixa Postal 176, CEP 37200-000 Lavras, MG. E-mail: vania.silva@epamig.br, ester@epamig.br, evandro_asj@yahoo.com.br ${ }^{(2)}$ Universidade Federal de Lavras, Departamento de Engenharia agrícola, Caixa Postal 3037, CEP 37200-000 Lavras, MG. E-mail: lalima@ufla.br, matheus-colares@hotmail.com ${ }^{(3)}$ Recursos Humanos no Agronegócio (ReHAgro), Avenida Uruguai, no 620, Bairro Sion, CEP 30310-300 Belo Horizonte, MG. E-mail: fabricio.andrade@rehagro.com.br ${ }^{(4)}$ Universidade Estadual Paulista, Campus de Botucatu, Fazenda Lageado, Portaria II, Rodovia Alcides Soares, Km 3, CEP 18610-307 Botucatu. E-mail: moreira.laislorena@yahoo.com.br
\end{abstract}

Resumo - O objetivo deste trabalho foi determinar o sistema de plantio de abacaxizeiro intercalado com cafeeiro que proporciona o maior retorno econômico, sem comprometer o desenvolvimento vegetativo e a produtividade de cafezal irrigado. Utilizou-se o delineamento em blocos ao acaso, com quatro repetições e dez plantas úteis por parcela. Os sistemas irrigados de cultivo consistiram em: duas e três fileiras simples de abacaxizeiro, nas entrelinhas do cafeeiro, ou quatro linhas em fileiras duplas. O desenvolvimento vegetativo do cafeeiro foi avaliado aos 6,12 e 18 meses após o plantio, e a produtividade aos 28 meses. O cultivo de duas fileiras simples favoreceu o desenvolvimento do cafeeiro, e os demais sistemas não tiveram efeito sobre esse parâmetro. A produtividade do cafeeiro foi maior nos sistemas de cultivo com duas e três fileiras de abacaxi. Os três sistemas de cultivo apresentaram retornos econômicos positivos. O sistema intercalar com três fileiras simples proporciona o melhor retorno, sem comprometer o desenvolvimento vegetativo e a produtividade do cafeeiro.

Termos para indexação: Ananas comosus, Coffea arabica, agricultura familiar, coeficientes técnicos, retorno econômico, sistemas de cultivo irrigado, sistemas intercalares.

\section{Pineapple intercropped systems as an income alternative during the formation of irrigated coffee crop}

\begin{abstract}
The objective of this work was to determine the planting system of pineapple intercropped with coffee plants that provides the highest economic return, without harming the vegetative development and yield of the irrigated coffee crop. A randomized complete block design was used, with four replicates and ten useful plants per plot. The irrigated cropping systems consisted of two and three single rows of pineapple between coffee rows, or of two double rows of pineapples. Vegetative development of the coffee plants was evaluated at 6,12 , and 18 months after planting, and the coffee yield at 28 months. Cultivation of two single rows of pineapple improved coffee development, and the other planting systems did not harm coffee development. Coffee yield was greater in the cropping systems with two and three intercropped rows of pineapples. The three planting systems had positive economic return. The system with three single rows provide the best economic return, without compromising the vegetative growth and yield of coffee plants.

Index terms: Ananas comosus, Coffea arabica, family farming, technical coefficients, economic return, irrigated cropping systems, intercropping.
\end{abstract}

\section{Introdução}

O Brasil é o principal produtor e exportador de café, com cerca de $30 \%$ da produção mundial. Neste cenário, Minas Gerais destaca-se como o maior estado produtor de café arábica do país (Companhia Nacional do Abastecimento, 2011). A cafeicultura mineira tem sua produção distribuída, principalmente, nas regiões sul de Minas, Zona da Mata, Triângulo Mineiro e Vale do Jequitinhonha.

No norte de Minas, a cafeicultura é recente, com plantios realizados há menos de 20 anos, concentrados no perímetro irrigado no entorno do Rio São Francisco, com boas perspectivas de se tornar uma nova zona cafeeira do estado (Camargos et al., 2011). O clima semiárido da região não tem sido limitante à 
atividade, pois a variabilidade temporal e espacial da precipitação tem sido superada pelo uso da irrigação, e a cafeicultura tem se mostrado tecnicamente viável ao se considerar o crescimento das plantas durante todo o ano, a facilidade na mecanização, a ausência de geadas e o menor custo das terras.

Um dos principais entraves na implantação da cafeicultura irrigada está relacionado ao alto investimento inicial, especialmente em obras e na aquisição de equipamentos, além dos gastos adicionais com água, energia e mão de obra para operação do sistema de irrigação (Oliveira et al., 2010). Diante disso, a maximização da utilização dos recursos ambientais e da mão de obra é fundamental, sobretudo para a sustentabilidade da agricultura familiar (Asten et al., 2011). Quando se considera que as lavouras cafeeiras devem ser irrigadas desde a sua formação e que, nessa fase, não há produção, uma alternativa para otimizar a utilização da irrigação e para a geração de renda para o pequeno agricultor é o plantio de culturas intercalares ao cafeeiro.

O norte de Minas Gerais é uma região que apresenta comprovado potencial para a fruticultura tropical, o que torna esta atividade uma potencial opção para o cultivo intercalar ao cafeeiro. Entre as frutíferas produtivas e com valor de mercado na região, o abacaxizeiro se destaca por ser uma fruta tropical tradicionalmente cultivada nas regiões mais quentes, e por possuir ciclo bianual (Maia et al., 2009). Estas características podem viabilizar seu cultivo intercalar durante a fase de formação do cafezal.

No Brasil, o abacaxizeiro pode ser plantado em sistema de fileiras simples ou duplas (Souza et al., 2009); entretanto, não há informações sobre qual sistema de plantio é mais adequado para o cultivo intercalar ao cafeeiro. O sistema ideal seria aquele que não prejudicasse o desenvolvimento e a produtividade do cafeeiro, em comparação ao monocultivo. Além disso, deve-se considerar o retorno econômico proporcionado pela cultura intercalar. Estudos de viabilidade econômica são realizados a partir dos fundamentos teóricos da "análise de projetos". Segundo Buarque (1991), a análise de projetos privados considera a geração de benefícios pelos projetos e as expectativas do proprietário, que avalia os aspectos financeiros e econômicos. Os indicadores de viabilidade econômica mais utilizados são o valor presente líquido (VPL) e a taxa interna de retorno (TIR). De acordo com Contador
(1981), esses indicadores são essenciais para a aceitação e a classificação da rentabilidade dos projetos.

O objetivo deste trabalho foi determinar o melhor sistema de plantio do abacaxizeiro intercalado com cafeeiro, que proporcione maior retorno econômico, sem comprometer o desenvolvimento vegetativo e a produtividade do cafezal irrigado.

\section{Material e Métodos}

O experimento foi conduzido na Fazenda Experimental de Mocambinho, pertencente à Empresa de Pesquisa Agropecuária de Minas Gerais, localizada no Projeto Jaíba, no extremo norte do estado $\left(15^{\circ} 05^{\prime} \mathrm{S}\right.$ e $44^{\circ} 00^{\prime} \mathrm{W}$, a $452 \mathrm{~m}$ de altitude). O clima da região é caracterizado como semiárido, com relevo plano e solo aluvial siltoso. A precipitação média anual é de $750 \mathrm{~mm}$, concentrada de novembro a março. A região apresenta médias anuais de $28^{\circ} \mathrm{C}, 9,5$ horas por dia de insolação e $48 \%$ de umidade relativa.

Para a condução do experimento, em janeiro de 2010 foi plantado café 'Catuaí Vermelho IAC 144', no espaçamento de 3,5x0,6 m. Em março de 2010, plantou-se o abacaxizeiro (Ananas comosus var. comosus), variedade Pérola, intercalado ao cafeeiro, nos seguintes sistemas de plantio: duas fileiras simples com espaçamento de $1,1 \times 0,33 \mathrm{~m}$; três fileiras simples com espaçamento de $0,95 \times 0,33 \mathrm{~m}$; e quatro linhas organizadas em fileiras duplas, no espaçamento de $0,9 \times 0,4 \times 0,33 \mathrm{~m}$. O cafeeiro em monocultivo foi utilizado como testemunha.

Utilizou-se sistema de irrigação por aspersão convencional, com aspersores do modelo LowFlow, com bocal cinza e bailarina verde. A 24 mca de pressão, o aspersor aplica $850 \mathrm{~L}$ por hora, com raio de alcance de $10,8 \mathrm{~m}$. Os aspersores foram espaçados em $12 \times 14 \mathrm{~m}$, com taxa de aplicação de água de 5,05 mm por hora.

As medições dos parâmetros biométricos do cafeeiro foram realizadas aos 6,12 e 18 meses após o plantio. As variáveis analisadas foram: diâmetro de caule (DC), número de ramos plagiotrópicos (NRP), altura das plantas (AP), comprimento do primeiro ramo plagiotrópico (CRP) e número de entrenós do primeiro ramo plagiotrópico (NNRP). Aos 28 meses após o plantio do cafeeiro, em maio de 2012, foi realizada a primeira colheita do cafeeiro. Foram avaliados: produtividade de café beneficiado, em sacas de $60 \mathrm{~kg} \mathrm{ha}^{-1}$ por ano; rendimento (\%); percentagem de frutos chochos; e classificação quanto à peneira (Brasil, 2003). 
Utilizou-se o delineamento experimental em blocos ao acaso, com quatro repetições e dez plantas úteis por parcela. Foi adotado o arranjo de parcelas subdivididas no tempo (Steel \& Torrie, 1980), em que os tratamentos constituíram a parcela e as épocas a subparcela. A análise de variância foi realizada por meio do programa Sisvar, e as médias foram comparadas pelo teste de Tukey, a 5\% de probabilidade.

Para o plantio do abacaxizeiro, o solo entre as linhas do cafeeiro foi preparado com uma aração e uma gradagem. O plantio foi feito manualmente, tendo-se aplicado $15 \mathrm{~g}$ de fosfato de monoamônio e $1 \mathrm{~g}$ de sulfato de zinco por cova. Foram efetuadas quatro adubações de cobertura, o que totalizou 37,5 g de sulfato de amônio e $25 \mathrm{~g}$ de cloreto de potássio por planta, aplicados nas axilas das folhas mais velhas. Foram obtidas mudas tipo rebentão. As mudas foram submetidas à cura, para eliminar o excesso de umidade, selecionadas e padronizadas de acordo com peso, tamanho e sanidade. Todas as mudas passaram por tratamento em solução aquosa de fungicida à base de fosetil, grupo químico fosfonato, nome comercial Aliette $\left(40 \mathrm{~g} \mathrm{~L}^{-1}\right.$ do produto comercial), e de inseticida à base de dimetoato, grupo químico organofosforado, nome comercial Dimetoato EC (1,5 mL L $\left.{ }^{-1}\right)$. A indução floral foi realizada aos oito meses do plantio, com preparo de $20 \mathrm{~L}$ de solução à base de etefon a $100 \mathrm{~mL}$ p.c., mais $400 \mathrm{~g}$ de ureia e $7 \mathrm{~g}$ de cal de água. A aplicação da solução foi feita sobre a roseta foliar, no final da tarde, na dosagem de $30 \mathrm{~mL}$ por planta. A produção foi colhida em março de 2011, tendo-se avaliado a produtividade e as características físico-químicas dos frutos de abacaxi.

Após a colheita, os frutos de abacaxi foram imediatamente transportados para o Laboratório de Pós-Colheita da Unidade Regional Epamig do Sul de Minas, onde foram realizadas as seguintes análises: peso médio do fruto com e sem coroa, em balança semianalítica com precisão de $0,001 \mathrm{~g}$; diâmetro e altura dos frutos, com leitura direta em paquímetro; $\mathrm{pH}$ em pHmetro digital, tendo-se considerado o valor do ácido principal como se este fosse o único presente; sólidos solúveis, com leitura direta em refratômetro digital; e acidez total titulável, obtida em $10 \mathrm{~mL}$ de suco, no qual foram adicionadas três gotas de indicador (solução alcoólica de fenolftaleina), com posterior titulação com solução de hidróxido de sódio 0,1 N (Cuniff, 1997).

Os indicadores de viabilidade econômica determinados foram o valor presente líquido (VPL) e a taxa interna de retorno (TIR). O VPL é o retorno do investimento, descontado o valor do dinheiro no tempo a uma taxa exógena, também definida como taxa de desconto. Portanto, o VPL é o somatório dos saldos de caixa líquidos (descontados), obtidos na vida útil do projeto. A taxa de desconto foi equivalente ao rendimento real médio da taxa do sistema especial de liquidação e custódia (Selic), no período compreendido entre 2010 e 2012. O rendimento real foi a diferença entre a taxa Selic e o índice de preços ao consumidor amplo (IPCA). A taxa de desconto calculada foi $4,50 \%$ ao ano. O VPL é calculado pela equação,

$\sum_{\mathrm{t}=0}^{\mathrm{n}}(\mathrm{E}-\mathrm{S})_{\mathrm{t}} /(1+\mathrm{i})^{\mathrm{t}}$,

em que: E são as entradas de caixa; $\mathrm{S}$ são as saídas de caixa; i é a taxa de desconto; e t é o período relativo a um saldo de caixa. Tal que: $\mathrm{VPL}>0$, viável; $\mathrm{VPL}=0$, rendimento igual à taxa de desconto, portanto, indiferente; VPL $<0$, inviável. A taxa interna de retorno (TIR) representa a taxa de desconto endógena gerada pelo projeto que torna o VPL igual a zero, a qual é definida como a taxa de juros composta oferecida pelo projeto. Esta taxa é expressa pela equação:

$\sum_{\mathrm{t}=0}^{\mathrm{n}}(\mathrm{E}-\mathrm{S})_{\mathrm{t}} /(1+\mathrm{TIR})^{\mathrm{t}}$

Para a elaboração desses indicadores, estruturaram-se os fluxos de caixa dos projetos; neste caso, os tratamentos. Os fluxos de caixa compreendem as entradas (receitas) e as saídas de caixa (desembolsos) a partir de 2010, quando o café foi plantado e o sistema de irrigação foi montado. No primeiro período, ocorreram apenas saídas de caixa em razão da implantação do café e do investimento em irrigação. Em 2011, as entradas de caixa corresponderam apenas às receitas oriundas do abacaxi, às saídas de caixa, ao plantio do abacaxi e aos tratos culturais das duas culturas. Em 2012, as entradas e as saídas de caixa corresponderam somente à cultura do café, pois esta produziu sua primeira safra e os abacaxizeiros já haviam sido removidos. As entradas de caixa da cultura do café foram calculadas pela multiplicação entre a produtividade e a média dos preços diários do café tipo 6 bebida dura, em 2012, coletados pelo Centro de Estudos em Economia Aplicada (Cepea/USP). Assim, para cada tratamento e em cada período, calculou-se um saldo de caixa. Os resultados fornecidos foram relativos

Pesq. agropec. bras., Brasília, v.47, n.10, p.1471-1479, out. 2012 
ao cultivo de 1 ha, e os coeficientes técnicos para o café e o abacaxi estão descritos nas Tabelas 1 e 2 , respectivamente.

Por se tratar de uma proposta para a agricultura familiar, tendo-se previsto a disponibilidade da terra e o uso de mão de obra familiar, não foram levados em consideração os custos com encargos trabalhistas e o investimento com a terra.

Tabela 1. Coeficientes técnicos e operações para implantação e manutenção de 1 ha de cafeeiro, em diferentes sistemas de cultivo intercalares com abacaxizeiro, do plantio até a primeira produção.

\begin{tabular}{|c|c|c|c|c|}
\hline \multirow[t]{2}{*}{ Insumos } & \multicolumn{4}{|c|}{ Sistema de cultivo $^{(1)}$} \\
\hline & Monocultivo & $\mathrm{C}+2 \mathrm{~A}$ & $\mathrm{C}+3 \mathrm{~A}$ & $\mathrm{C}+4 \mathrm{~L} 2 \mathrm{~A}$ \\
\hline Mudas de café (Unidade) & 5.238 & 5.238 & 5.238 & 5.238 \\
\hline Adubo orgânico $\left(\mathrm{m}^{3}\right)$ & 11,14 & 11,14 & 11,14 & 11,14 \\
\hline Calcário dolomítico (Sc) & 4 & 4 & 4 & 4 \\
\hline Superfosfato simples (kg) & 755 & 755 & 755 & 755 \\
\hline Fórmula 20-05-20 (kg) & 238,1 & 238,1 & 238,1 & 238,1 \\
\hline Fórmula 20-00-20 (kg) & 334 & 334 & 334 & 334 \\
\hline Sulfato de amônio (kg) & 4.286 & 4.286 & 4.286 & 4.286 \\
\hline Cloreto de potássio (kg) & 1.714 & 1.714 & 1.714 & 1.714 \\
\hline Sulfato de zinco (kg) & 3,34 & 3,34 & 3,34 & 3,34 \\
\hline Oxicloreto de cobre $(\mathrm{kg})$ & 1 & 1 & 1 & 1 \\
\hline Inseticida/ Acaricida (kg) & 3 & 3 & 3 & 3 \\
\hline Fungicida (kg) & 3 & 3 & 3 & 3 \\
\hline Ácido fosfórico (L) & 0,1 & 0,1 & 0,1 & 0,1 \\
\hline Espalhante adesivo (L) & 0,8 & 0,8 & 0,8 & 0,8 \\
\hline Roundup (L) & 2 & 2 & 2 & 2 \\
\hline \multicolumn{5}{|c|}{ Mão de obra no preparo de solo, adubação e plantio } \\
\hline Gradagem pesada (HM) & 1,5 & 1,5 & 1,5 & 1,5 \\
\hline Nivelação (HM) & 1 & 1 & 1 & 1 \\
\hline Sulcação (HM) & 0,7 & 0,7 & 0,7 & 0,7 \\
\hline Plantio (HM) & 25 & 25 & 25 & 25 \\
\hline Coveamento (HM) & 2 & 2 & 2 & 2 \\
\hline Marcação da área (HM) & 2 & 2 & 2 & 2 \\
\hline Adubação de plantio (HM) & 5 & 5 & 5 & 5 \\
\hline Replantio (HM) & 3 & 3 & 3 & 3 \\
\hline \multicolumn{5}{|c|}{ Mão de obra nos tratos culturais e fitossanitários } \\
\hline Adubação manual (HM) & 26,5 & 1,5 & 1,5 & 1,5 \\
\hline Aplicação de esterco (HM) & 2 & 1 & 1 & 1 \\
\hline Aplicação manual de defensivo (HM) & 20 & 0,7 & 0,7 & 0,7 \\
\hline Capina manual (HM) & 68 & 25 & 25 & 25 \\
\hline Capina mecânica (HM) & 2 & 2 & 2 & 2 \\
\hline Capina química (HM) & 2 & 2 & 2 & 2 \\
\hline Colheita, secagem, beneficiamento ( & (HM) 85 & 124 & 118 & 94 \\
\hline Consumo de energia elétrica (Kwh) & 4.712 & 4.712 & 4.712 & 4.712 \\
\hline Mão de obra (HM) & 32 & 32 & 32 & 32 \\
\hline Água $\left(1.000 \mathrm{~m}^{3}\right)$ & 36 & 36 & 36 & 36 \\
\hline
\end{tabular}

${ }^{(1)} \mathrm{C}+2 \mathrm{~A}$, cafeeiro com duas fileiras intercalares de abacaxizeiro; $\mathrm{C}+3 \mathrm{~A}$, cafeeiro com três fileiras de abacaxizeiro; $\mathrm{C}+4 \mathrm{~L} 2 \mathrm{~A}$, cafeeiro com quatro linhas em fileiras duplas de abacaxizeiro. HD, dia homem; HM, hora máquina.

\section{Resultados e Discussão}

Aos seis meses após o plantio do cafeeiro, não foram observadas diferenças significativas para nenhum parâmetro biométrico avaliado (Tabela 3). Nesse estágio, havia três meses do plantio do abacaxi e, portanto, as plantas ainda estavam em estádio fenológico inicial, sem capacidade para afetar o crescimento do cafeeiro.

Aos 12 meses após o plantio, quando o abacaxizeiro estava em fase de crescimento dos frutos, o cafeeiro intercalado com duas fileiras simples de abacaxi apresentou melhor desempenho em relação aos parâmetros CRP e NERP, em comparação ao cafeeiro em monocultivo. Entretanto, os cafeeiros intercalados com três fileiras ou com duas fileiras duplas de abacaxi não diferiram do cafeeiro em monocultivo, quanto aos parâmetros biométricos. Nessa fase, observou-se que as

Tabela 2. Coeficientes técnicos e operações para implantação e manutenção de 1 ha de abacaxizeiro em diferentes sistemas de plantios intercalares ao cafeeiro (um ciclo do abacaxizeiro).

\begin{tabular}{lccc}
\hline Insumos & \multicolumn{3}{c}{ Sistema de cultivo $^{(1)}$} \\
\cline { 2 - 4 } & $\mathrm{C}+2 \mathrm{~A}$ & $\mathrm{C}+3 \mathrm{~A}$ & $\mathrm{C}+4 \mathrm{~L} 2 \mathrm{~A}$ \\
\hline Mudas de abacaxi (Unidade) & 17.460 & 26.190 & 34.920 \\
Dimetoato (L) & 0,8 & 2,4 & 1,8 \\
Alliete (kg) & 0,65 & 1 & 1,2 \\
Sulfato de amônio (kg) & 675 & 1.012 & 1.518 \\
Cloreto de potássio (kg) & 450 & 674 & 1.012 \\
Fosfato de monoamônio (kg) & 270 & 404 & 607 \\
Sulfato de zinco (kg) & 18 & 27 & 36 \\
Ethel (L) & 0,7 & 0,9 & 1,3 \\
Ureia (kg) & 1 & 1,3 & 2 \\
Cal (kg) & 0,2 & 0,35 & 0,4 \\
\hline Mão de obra no preparo de solo, adubação e plantio & \\
Aração (HM) & 1,11 & 1,11 & 1,11 \\
Gradagem (HM) & 0,82 & 0,82 & 0,82 \\
Adubação de plantio (HD) & 15 & 18 & 30 \\
Plantio (HD) & 15 & 18 & 30 \\
\hline Mão de obra nos tratos culturais e fitossanitários & \\
Tratamento das mudas (HD) & 3 & 4 & 4 \\
Tratamento das mudas (HD) & 3 & 4 & 4 \\
Adubação (HD) & 15 & 20 & 20 \\
Indução floral (HD) & 15 & 15 & 26 \\
Capinas (HD) & 58 & 68 & 72 \\
Proteção dos frutos (HD) & 17 & 20 & 30 \\
Colheita (HD) & 18 & 30 & 35 \\
\hline
\end{tabular}

${ }^{(1)} \mathrm{C}+2 \mathrm{~A}$, cafeeiro com duas fileiras intercalares de abacaxizeiro; $\mathrm{C}+3 \mathrm{~A}$, cafeeiro com três fileiras de abacaxizeiro; $\mathrm{C}+4 \mathrm{~L} 2 \mathrm{~A}$, cafeeiro com quatro linhas em fileiras duplas de abacaxizeiro. HD, dia homem; HM, hora máquina. 
plantas de café em sistemas de cultivo intercalados com o abacaxi apresentaram DC, AP e NRP semelhantes.

Aos 18 meses de idade do cafeeiro, o abacaxi já havia sido colhido há três meses. Nessa avaliação, foi possível observar que o cafeeiro cultivado com duas fileiras simples de abacaxi apresentou DC, AP e NRP semelhantes ao cafeeiro cultivado com três fileiras, mas superiores ao cafeeiro intercalado com

Tabela 3. Valores médios de diâmetro de caule, altura de planta, número de ramos plagiotrópicos, comprimento do primeiro ramo plagiotrópico e número de entrenós do primeiro ramo plagiotrópico do cafeeiro, em diferentes sistemas de cultivo intercalares com abacaxizeiro ${ }^{(1)}$.

\begin{tabular}{|c|c|c|c|c|}
\hline \multirow{2}{*}{$\begin{array}{l}\text { Tempo } \\
\text { (meses) }\end{array}$} & \multicolumn{4}{|c|}{ Sistemas de cultivo $^{(2)}$} \\
\hline & Monocultivo & $\mathrm{C}+2 \mathrm{~A}$ & $\mathrm{C}+3 \mathrm{~A}$ & $\mathrm{C}+4 \mathrm{~L} 2 \mathrm{~A}$ \\
\hline & \multicolumn{4}{|c|}{ Diâmetro do caule (cm) } \\
\hline 6 & $0,65 \mathrm{a}$ & $0,68 \mathrm{a}$ & $0,66 \mathrm{a}$ & $0,65 \mathrm{a}$ \\
\hline 12 & $1,15 \mathrm{a}$ & $1,64 \mathrm{a}$ & $1,27 \mathrm{a}$ & $1,15 \mathrm{a}$ \\
\hline \multirow[t]{2}{*}{18} & $2,22 \mathrm{~b}$ & $2,85 \mathrm{a}$ & $2,56 \mathrm{ab}$ & $2,25 \mathrm{~b}$ \\
\hline & \multicolumn{4}{|c|}{ Altura de planta $(\mathrm{cm})$} \\
\hline 6 & $39,95 \mathrm{a}$ & $38,47 \mathrm{a}$ & $37,90 \mathrm{a}$ & $35,82 \mathrm{a}$ \\
\hline 12 & $57,20 \mathrm{~b}$ & $73,70 \mathrm{a}$ & $65,40 \mathrm{ab}$ & $60,65 b$ \\
\hline \multirow[t]{2}{*}{18} & $76,20 \mathrm{c}$ & $102,00 \mathrm{a}$ & $93,33 \mathrm{ab}$ & $84,33 \mathrm{bc}$ \\
\hline & \multicolumn{4}{|c|}{ Número de ramos plagiotrópicos } \\
\hline 6 & $6,62 \mathrm{a}$ & $6,47 \mathrm{a}$ & $6,84 \mathrm{a}$ & $5,00 \mathrm{a}$ \\
\hline 12 & $20,16 b$ & $25,22 \mathrm{a}$ & $23,93 \mathrm{ab}$ & $22,98 \mathrm{ab}$ \\
\hline \multirow[t]{2}{*}{18} & $27,71 \mathrm{c}$ & $36,67 \mathrm{a}$ & $35,54 \mathrm{ab}$ & $32,35 b$ \\
\hline & \multicolumn{4}{|c|}{ Comprimento do primeiro ramo plagiotrópico $(\mathrm{cm})$} \\
\hline 6 & $14,42 \mathrm{a}$ & $14,57 \mathrm{a}$ & $14,30 \mathrm{a}$ & $11,88 \mathrm{a}$ \\
\hline 12 & $30,75 \mathrm{bc}$ & $45,80 \mathrm{a}$ & $34,24 b$ & $26,99 \mathrm{c}$ \\
\hline \multirow[t]{2}{*}{18} & $42,43 b$ & $59,32 \mathrm{a}$ & $47,53 \mathrm{~b}$ & $45,39 \mathrm{~b}$ \\
\hline & \multicolumn{4}{|c|}{ Número de entrenós do primeiro ramo plagiotrópico } \\
\hline 6 & $2,22 \mathrm{a}$ & $2,52 \mathrm{a}$ & $2,42 \mathrm{a}$ & $1,89 \mathrm{a}$ \\
\hline 12 & $12,50 \mathrm{~b}$ & $14,87 \mathrm{a}$ & $12,93 \mathrm{~b}$ & $11,65 b$ \\
\hline 18 & $16,40 \mathrm{~b}$ & $19,50 \mathrm{a}$ & $17,27 b$ & $18,10 \mathrm{ab}$ \\
\hline
\end{tabular}

(1)Médias seguidas de letras iguais, nas linhas, não diferem pelo teste de Tukey, a $5 \%$ de probabilidade. ${ }^{(2)} \mathrm{C}+2 \mathrm{~A}$, cafeeiro com duas fileiras de abacaxizeiro; $\mathrm{C}+3 \mathrm{~A}$, cafeeiro com três fileiras de abacaxizeiro; $\mathrm{C}+4 \mathrm{~L} 2 \mathrm{~A}$, cafeeiro com quatro linhas em fileiras duplas de abacaxizeiro. quatro linhas em fileiras duplas e ao cafeeiro em monocultivo. Os cafeeiros intercalados com quatro linhas em fileiras duplas de abacaxi não diferiram do cafeeiro em monocultivo. Portanto, o desenvolvimento inicial do cafeeiro foi favorecido pelo cultivo intercalar de abacaxizeiro com duas fileiras simples e não foi prejudicado nos sistemas intercalares de três fileiras e quatro linhas em fileiras duplas. Este resultado pode ser atribuído ao melhor condicionamento do solo, proporcionado pelo cultivo intercalar (Balota \& Auler, 2011), e à possível redução das temperaturas máximas no microambiente de cultivo, o que teria preservado a água e reduzido a alta evaporação, característica do semiárido de Minas Gerais.

Os cafeeiros cultivados com duas e três fileiras simples de abacaxi também apresentaram maior produtividade do que o monocultivo e o cafeeiro com quatro linhas em fileiras duplas (Tabela 4). Este último não interferiu de maneira significativa na primeira produtividade do café, pois apresentou produtividade similar à do cafeeiro em monocultivo. As produtividades dos cafeeiros cultivados com duas e três fileiras simples de abacaxi intercalares foram altas e semelhantes às produtividades de café irrigado em monocultivos de regiões tradicionais, como o cerrado mineiro, o oeste da Bahia e o sul de Minas Gerais (Carvalho et al., 2010; Evangelista et al., 2011).

O cultivo de abacaxi, independentemente do sistema de produção, não influenciou o rendimento, a classificação quanto à peneira e a percentagem de frutos de café chochos. O rendimento de café em coco para café beneficiado foi de aproximadamente $50 \%$, considerado bom (Paiva et al., 2010). De acordo com a classificação do café por peneira, $44,37 \%$ dos frutos foram classificados como chato graúdo e $36,89 \%$ como chato médio, o que está de acordo com as características reportadas para a cultivar Catuaí Vermelho IAC 144

Tabela 4. Produtividade, renda média e percentagem de grãos chatos graúdos, médios, moca e chochos do cafeeiro, em diferentes sistemas de cultivo intercalares com abacaxizeiro.

\begin{tabular}{|c|c|c|c|c|c|c|}
\hline Sistema de produção & $\begin{array}{l}\text { Sacas beneficiadas } \\
\text { por ha }\end{array}$ & Renda & Chato graúdo & Chato médio & Moca & Chochos \\
\hline Duas fileiras simples & $44,75 b$ & $51,00 \mathrm{a}$ & $38,75 \mathrm{a}$ & $39,25 \mathrm{a}$ & $11,50 \mathrm{a}$ & $9,50 \mathrm{a}$ \\
\hline Três fileiras simples & $42,50 \mathrm{~b}$ & $50,25 \mathrm{a}$ & $44,75 \mathrm{a}$ & $38,00 \mathrm{a}$ & $10,75 \mathrm{a}$ & $13,00 \mathrm{a}$ \\
\hline Quatro linhas em fileiras duplas & $34,00 \mathrm{a}$ & $48,50 \mathrm{a}$ & $44,00 \mathrm{a}$ & $37,75 \mathrm{a}$ & $11,50 \mathrm{a}$ & $9,00 \mathrm{a}$ \\
\hline Cafeeiro em monocultivo & $28,75 \mathrm{a}$ & $48,50 \mathrm{a}$ & $50,00 \mathrm{a}$ & $32,50 \mathrm{a}$ & $9,50 \mathrm{a}$ & $8,50 \mathrm{a}$ \\
\hline Média & 37,50 & 49,56 & 44,37 & 36,89 & 10,81 & 10,00 \\
\hline $\mathrm{CV}(\%)$ & 17,17 & 3,05 & 15,62 & 12,73 & 22,46 & 64,29 \\
\hline
\end{tabular}


(Botelho et al., 2010). O percentual médio de grãos do tipo moca foi de $10,81 \%$. Isso indica que os cafés produzidos nesses sistemas apresentaram percentagem de peneira alta e boa granação. Além disso, na análise da percentagem de frutos chochos, observou-se baixa ocorrência de "lojas vazias", com média de $10 \%$. Assim, os cafeeiros cultivados nos diferentes sistemas intercalares de cultivo com abacaxizeiro apresentaram, aproximadamente, percentual de $90 \%$ de frutos bem granados, o que é considerado satisfatório (Carvalho et al., 2006).

A produtividade do abacaxizeiro foi menor na menor densidade de plantio, com $17 \mathrm{Mg} \mathrm{ha}^{-1}$ obtidas nas duas fileiras simples (Tabela 5). Já no sistema com três fileiras e com fileiras duplas, a produtividade foi de 25,5 e 26,25 $\mathrm{Mg} \mathrm{ha}^{-1}$, respectivamente. Portanto, a produção no sistema de três fileiras não diferiu significativamente da observada no sistema com quatro linhas em fileiras duplas de abacaxizeiro.

Não houve diferença nos parâmetros físicos dos frutos, entre os sistemas de cultivo avaliados. Os frutos, apresentaram peso médio de $1 \mathrm{~kg}$ em todos os sistemas. Esse resultado significa que os frutos são comercializáveis e classificados na classe I (Brasil, 2002). O comprimento e o diâmetro dos frutos de abacaxi também estiveram dentro dos limites comercializáveis. Quanto aos parâmetros químicos avaliados, somente o $\mathrm{pH}$ dos frutos não diferiu significativamente nos tratamentos testados. Independentemente do sistema de plantio intercalar e das diferenças observadas entre eles, os valores de Brix,

Tabela 5. Produtividade e características do abacaxi 'Pérola' intercalado ao cafeeiro em diferentes sistemas de cultivo intercalares ${ }^{(1)}$.

\begin{tabular}{lcccr}
\hline Parâmetros & \multicolumn{4}{c}{ Sistema de cultivo ${ }^{(2)}$} \\
\cline { 2 - 5 } & $\mathrm{C}+2 \mathrm{~A}$ & $\mathrm{C}+3 \mathrm{~A}$ & $\mathrm{C}+4 \mathrm{~L} 2 \mathrm{~A}$ & $\mathrm{CV}(\%)$ \\
\hline${\text { Produtividade }\left(\mathrm{Mg} \mathrm{ha}^{-1}\right)}^{17,00 \mathrm{a}}$ & $25,50 \mathrm{~b}$ & $26,25 \mathrm{~b}$ & 10,66 \\
Número de frutos por ha $^{-1}$ & $15.476,50 \mathrm{a}$ & $22.553,00 \mathrm{~b}$ & $24.768,50 \mathrm{~b}$ & 8,39 \\
Plantas não produzidas $(\%)$ & $95,75 \mathrm{a}$ & $94,75 \mathrm{a}$ & $78,00 \mathrm{~b}$ & 28,00 \\
Peso (kg) & $1,020 \mathrm{a}$ & $1,035 \mathrm{a}$ & $1,088 \mathrm{a}$ & 18,26 \\
Peso da coroa $(\mathrm{kg})$ & $0,091 \mathrm{a}$ & $0,118 \mathrm{a}$ & $0,125 \mathrm{a}$ & 25,35 \\
Comprimento $(\mathrm{cm})$ & $17,995 \mathrm{a}$ & $18,790 \mathrm{a}$ & $19,655 \mathrm{a}$ & 10,86 \\
Diâmetro (cm) & $9,705 \mathrm{a}$ & $9,505 \mathrm{a}$ & $9,765 \mathrm{a}$ & 5,29 \\
pH & $3,60 \mathrm{a}$ & $3,61 \mathrm{a}$ & $3,58 \mathrm{a}$ & 2,52 \\
Acidez titulável $(\%)$ & $0,70 \mathrm{a}$ & $0,83 \mathrm{~b}$ & $0,84 \mathrm{~b}$ & 11,72 \\
${ }^{\circ}$ Brix & $13,557 \mathrm{a}$ & $13,955 \mathrm{~b}$ & $14,385 \mathrm{~b}$ & 5,21 \\
\hline
\end{tabular}

${ }^{(1)}$ Médias seguidas de letras iguais, nas colunas, não diferem, entre si, pelo teste de Tukey, a $5 \%$ de probabilidade. ${ }^{(2)} \mathrm{C}+2 \mathrm{~A}$, cafeeiro com duas fileiras de abacaxizeiro; $\mathrm{C}+3 \mathrm{~A}$, cafeeiro com três fileiras de abacaxizeiro; C+4L2A, cafeeiro com quatro linhas em fileiras duplas de abacaxizeiro. acidez e da relação SST/AT foram satisfatórios, o que está dentro dos padrões exigidos para a comercialização da cultivar Pérola no Brasil, em suas principais regiões produtoras (Bengozi et al., 2007; Cunha et al., 2007; Pereira et al., 2009; Ferreira et al., 2011).

A adoção de plantios consorciados, que tem se mostrado mais apropriada para os agricultores familiares ou pequenos, deve ser precedida, também, de uma avaliação sobre os ganhos econômicos que o sistema pode proporcionar para esses produtores. O café é uma cultura perene, com vida útil superior a 20 anos, o que a caracteriza como um investimento com retorno em longo prazo (Lanna $\&$ Reis, 2012). No presente trabalho, apesar de terse considerado apenas uma produção de café, os indicadores de viabilidade permitiram definir qual sistema de plantio do abacaxizeiro gerou melhor retorno econômico.

Todos os tratamentos apresentaram VPL negativo, pois apenas três saldos de caixa (períodos) compuseram os cálculos (Tabela 6). No entanto, um VPL maior indica que os saldos de caixa foram maiores e propiciaram amortização mais rápida do investimento. O cultivo intercalar com três fileiras simples de abacaxi gerou o maior VPL $(-\mathrm{R} \$ 416,19)$, seguido pelo cultivo intercalar com duas fileiras simples $(-\mathrm{R} \$ 4.641,12)$; pelo cultivo intercalar com quatro linhas em fileiras duplas (-R\$6.721,11); e pelo monocultivo de café $(-\mathrm{R} \$ 19.234,91)$.

O cultivo de abacaxi gerou saldo de caixa positivo em todos os tratamentos, o que amortizou parte do investimento inicial com a formação da lavoura de café e com a irrigação. O maior saldo de caixa proporcionado pelo cultivo de abacaxi foi proveniente do cultivo intercalar com três fileiras simples $(\mathrm{R} \$ 13.322,14)$, seguido por quatro linhas em fileiras duplas $(\mathrm{R} \$ 9.977,16)$ e duas fileiras simples $(\mathrm{R} \$ 8.178,62)$. O cultivo de abacaxi com duas linhas duplas gerou a maior receita proveniente do abacaxi ( $\mathrm{R} \$ 26.250,00)$; no entanto, as saídas de caixa (-R $\$ 16.272,84)$ foram maiores quando comparadas às das três fileiras simples (-R\$12.177,86), o que gerou a segunda maior receita $(\mathrm{R} \$ 25.500,00)$. No cálculo de saída de caixa do abacaxi, os maiores valores observados ocorreram com a aquisição de mudas (40\%). Isso pode ser atribuído à indisponibilidade de mudas (qualidade e quantidade) na região. Os insumos utilizados para adubação do abacaxi corresponderam a $18 \%$, em decorrência da obtenção de mudas de qualidade e do 
Tabela 6. Fluxo de caixa e indicadores de avaliação da viabilidade econômica de diferentes sistemas de cultivo de abacaxizeiro intercalado ao cafeeiro, em Mocambinho, $\mathrm{MG}^{(1)}$.

\begin{tabular}{|c|c|c|c|}
\hline Período & 0 & 1 & 2 \\
\hline & \multicolumn{3}{|c|}{ Cafeeiro em monocultivo } \\
\hline \multicolumn{4}{|l|}{ Abacaxi } \\
\hline Entrada & - & - & - \\
\hline Saída & - & - & - \\
\hline Saldo & - & - & - \\
\hline Saldo acumulado & - & - & - \\
\hline \multicolumn{4}{|l|}{ Café } \\
\hline Entrada & - & - & $11.730,00$ \\
\hline Saída & $-12.354,72$ & $-9.021,76$ & $-9.815,60$ \\
\hline Saldo & $-12.354,72$ & $-9.021,76$ & $1.914,40$ \\
\hline Saldo acumulado & $-12.354,72$ & $-21.376,48$ & $-19.462,08$ \\
\hline \multicolumn{4}{|l|}{ Total } \\
\hline Saldo & $-12.354,72$ & $-9.021,76$ & $1.914,40$ \\
\hline Saldo acumulado & $-12.354,72$ & $-21.376,48$ & $-19.462,08$ \\
\hline VPL & $-19.234,91$ & - & - \\
\hline TIR & - & - & - \\
\hline & \multicolumn{3}{|c|}{ Duas fileiras simples de abacaxizeiro } \\
\hline \multicolumn{4}{|c|}{ 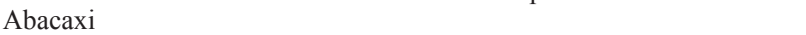 } \\
\hline Entrada & - & $17.000,00$ & - \\
\hline Saída & - & $-8.821,38$ & - \\
\hline Saldo & - & $8.178,62$ & - \\
\hline Saldo acumulado & - & $8.178,62$ & $8.178,62$ \\
\hline \multicolumn{4}{|l|}{ Café } \\
\hline Entrada & - & - & $18.258,00$ \\
\hline Saída & $-12.354,72$ & $-8.196,76$ & $-9.815,60$ \\
\hline Saldo & $-12.354,72$ & $-8.196,76$ & $8.442,40$ \\
\hline Saldo acumulado & $-12.354,72$ & $-20.551,48$ & $-12.109,08$ \\
\hline \multicolumn{4}{|l|}{ Total } \\
\hline Saldo & $-12.354,72$ & $-18,15$ & $8.442,40$ \\
\hline Saldo acumulado & $-12.354,72$ & $-12.372,86$ & $-3.930,46$ \\
\hline VPL & $-4.641,12$ & & \\
\hline TIR & \multirow{2}{*}{\multicolumn{3}{|c|}{ Três fileiras simples de abacaxizeiro }} \\
\hline \multirow{2}{*}{\multicolumn{4}{|c|}{ 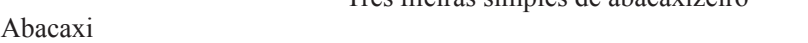 }} \\
\hline & & & \\
\hline Entrada & - & $25.500,00$ & - \\
\hline Saída & - & $-12.177,86$ & - \\
\hline Saldo & - & $13.322,14$ & - \\
\hline Saldo acumulado & - & $13.322,14$ & $13.322,14$ \\
\hline \multicolumn{4}{|l|}{ Café } \\
\hline Entrada & - & - & $17.340,00$ \\
\hline Saída & $-12.354,72$ & $-8.046,76$ & $-9.815,60$ \\
\hline Saldo & $-12.354,72$ & $-8.046,76$ & $7.524,40$ \\
\hline Saldo acumulado & $-12.354,72$ & $-20.401,48$ & $-12.877,08$ \\
\hline \multicolumn{4}{|l|}{ Total } \\
\hline Saldo & $-12.354,72$ & $5.275,37$ & $7.524,40$ \\
\hline Saldo acumulado & $-12.354,72$ & $-7.079,34$ & 445,06 \\
\hline VPL & $-416,19$ & - & - \\
\hline TIR & $2,30 \%$ & - & - \\
\hline & Quatro linha & $\mathrm{n}$ fileiras dup & e abacaxizeiro \\
\hline \multicolumn{4}{|c|}{ 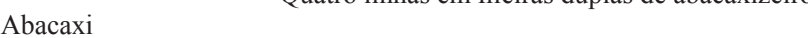 } \\
\hline Entrada & - & $26.250,00$ & - \\
\hline Saída & - & $-16.272,84$ & - \\
\hline Saldo & - & $9.977,16$ & - \\
\hline Saldo acumulado & - & $9.977,16$ & $9.977,16$ \\
\hline \multicolumn{4}{|l|}{ Café } \\
\hline Entrada & - & - & $13.872,00$ \\
\hline Saída & $-12.354,72$ & $-7.971,76$ & $-9.815,60$ \\
\hline Saldo & $-12.354,72$ & $-7.971,76$ & $4.056,40$ \\
\hline Saldo acumulado & $-12.354,72$ & $-20.326,48$ & $-16.270,08$ \\
\hline Saldo & $-12.354,72$ & $2.005,40$ & $4.056,40$ \\
\hline \multicolumn{4}{|l|}{ Total } \\
\hline Saldo acumulado & $-12.354,72$ & $-10.349,32$ & $-6.292,92$ \\
\hline VPL & $-6.721,11$ & & \\
\hline TIR & - & & \\
\hline
\end{tabular}

(1)VPL, valor presente líquido; TIR, taxa interna de retorno. tratamento das mudas com fungicida e inseticida antes do plantio. Não ocorreram pragas e doenças durante o ciclo da cultura; portanto, as saídas com defensivos e com o indutor floral representaram somente 1,3\% dos insumos utilizados para os tratos culturais e fitossanitários. A mão de obra correspondeu a 9\% das saídas, para preparo do solo e plantio, e a $5 \%$, para colheita. Os tratos culturais e fitossanitários foram compostos pelas operações de tratamento das mudas - adubação, indução floral, capinas e proteção dos frutos -, que juntas, contribuíram com 26,5\% das saídas. A operação de capina respondeu por metade dos custos dos tratos culturais, pois há grande crescimento de ervas espontâneas em razão do clima e da irrigação favoráveis.

No terceiro período, todos os tratamentos se tornaram monocultivos de cafeeiros, uma vez que os abacaxizeiros foram retirados da área após a colheita do abacaxi. Como os sistemas de cultivo se igualaram no terceiro período, com saídas de caixa iguais (-R $\$ 9.815,60)$, a receita proveniente do café se tornou a variável determinante. A maior receita com café foi oriunda do tratamento que continha duas fileiras simples de abacaxi ( $\mathrm{R} \$ 18.258,00)$, seguida do tratamento com três fileiras simples $(\mathrm{R} \$ 17.340,00)$, duas linhas duplas $(\mathrm{R} \$ 13.872,00)$ e do tratamento em monocultivo ( $\mathrm{R} \$ 11.730,00)$.

De uma perspectiva financeira, o saldo de caixa acumulado total, ao final dos três períodos, consistiu do efeito do saldo de caixa do cultivo de abacaxi e da primeira colheita do café. Quanto maiores os saldos, mais rapidamente o investimento inicial é amortizado. O maior saldo de caixa acumulado total foi observado no cultivo de café consorciado com três linhas de abacaxi (R $\$ 445,06)$, seguido por duas fileiras simples de abacaxi (-R \$3.930,46), duas linhas duplas de abacaxi (-R\$6.292,92) e pelo monocultivo (-R \$19.462,08).

$\mathrm{O}$ único tratamento a apresentar TIR positiva foi o cultivo de café consorciado com três fileiras simples de abacaxi (2,26\%). O retorno foi positivo, mas menor que a taxa de desconto utilizada, o que gerou VPL negativo. O VPL se tornaria positivo a partir de uma TIR de $4,50 \%$.

\section{Conclusões}

1. O cultivo de café consorciado com abacaxi apresenta retorno econômico superior ao monocultivo de café. 
2. O sistema intercalar com três fileiras simples de abacaxizeiro tem melhor retorno econômico e não compromete o desenvolvimento vegetativo e a produtividade do cafeeiro.

\section{Agradecimentos}

Ao Ministério do Desenvolvimento Agrário Secretaria de Agricultura Familiar, ao Ministério da Ciência e Tecnologia - Secretaria de Ciência e Tecnologia para Inclusão Social, ao Conselho Nacional de Desenvolvimento Científico e Tecnológico, ao Consórcio Brasileiro de Pesquisa e Desenvolvimento do Café e à Fundação de Amparo à Pesquisa do Estado de Minas Gerais, por suporte financeiro; à Empresa de Assistência Técnica e Extensão Rural do Estado de Minas Gerais e à Universidade Federal de Lavras, pelas parcerias.

\section{Referências}

ASTEN, P.J.A. van; WAIREGI, L.W.I.; MUKASA, D.; URINGI, N.O. Agronomic and economic benefits of coffee-banana intercropping in Uganda's smallholder farming systems. Agricultural Systems, v.104, p.326-334, 2011.

BALOTA, E.L.; AULER, P.A.M. Soil microbial biomass under different management and tillage systems of permanent intercropped cover species in an orange orchard. Revista Brasileira de Ciência do Solo, v.35, p.1873-1883, 2011.

BENGOZI, F.J.; SAMPAIO, A.C.; SPOTO, M.H.F.; MISCHAN, M.M.; PALLAMIN, M.L. Qualidades físicas e químicas do abacaxi comercializado na CEAGESP São Paulo. Revista Brasileira de Fruticultura, v.29, p.540-545, 2007.

BOTELHO, C.E.; REZENDE, J.C. de; CARVALHO, G.R.; CARVALHO, A.M. de; ANDRADE, V.T.; BARBOSA, C.R. Adaptabilidade e estabilidade fenotípica de cultivares de café arábica em Minas Gerais. Pesquisa Agropecuária Brasileira, v.45, p.1404-1411, 2010.

BRASIL. Ministério da Agricultura, Pecuária e Abastecimento. Instrução normativa $n^{0} 1$, de 1 de fevereiro de 2002. Aprova os regulamentos técnicos de identidade e de qualidade para a classificação do abacaxi, uva fina de mesa e uva rústica. Diário Oficial [da] República Federativa do Brasil, 4 fev. 2002.

BRASIL. Ministério da Agricultura, Pecuária e Abastecimento. Instrução normativa $\mathrm{n}^{\circ} 8$, de 11 de julho de 2003. Regula os procedimentos para apuração de infrações administrativas por condutas e atividades lesivas ao meio ambiente, a imposição das sanções, a defesa ou impugnação, o sistema recursal e a cobrança de créditos de natureza tributária e não tributária para com esta Autarquia. Diário Oficial [da] República Federativa do Brasil, 20 ago. 2003.
BUARQUE, C. Avaliação econômica de projetos. 6.ed. Rio de Janeiro: Campus, 1991. 266p.

CAMARGOS, M.G.; ALVARENGA, C.D.; GIUSTOLIN, T.A.; STRIKIS, P.C. Moscas frugívoras (Diptera: Lonchaeidae) em cafezais irrigados no norte de Minas Gerais. Revista Arquivos do Instituto Biológico, v.78, p.615-617, 2011.

CARVALHO, A.M. de; MENDES, A.N.G.; CARVALHO, G.R.; BOTELHO, C.E.; GONÇALVES, F.M.A.; FERREIRA, A.D. Correlação entre crescimento e produtividade de cultivares de café em diferentes regiões de Minas Gerais, Brasil. Pesquisa Agropecuária Brasileira, v.45, p.269-275, 2010.

CARVALHO, G.R.; BARTHOLO, G.F.; MENDES, A.N.G.; NOGUEIRA, Â.M.; MAGALHÃES, M.M. Seleção de progênies oriundas do cruzamento entre 'Catuaí' e 'Mundo Novo' em diferentes regiões do Estado de Minas Gerais. Bragantia, v.65, p.583-590, 2006.

COMPANHIA NACIONAL DE ABASTECIMENTO. Acompanhamento da safra brasileira: café: safra 2011: primeira estimativa: janeiro/2011. Brasília: Conab, 2011. Disponível em: <http://www.conab.gov.br/OlalaCMS/uploads/ arquivos/11_01_06_08_52_41_boletim_cafe_1a_estimativa_ safra_2011..pdf $>$. Acesso em: 1 fev. 2011.

CONTADOR, C.R. Avaliação social de projetos. São Paulo: Atlas, 1981. 301p.

CUNIFF, P. Official methods of analysis of AOAC International. $16^{\text {th }}$ ed. Gaithersburg: AOAC International, 1997. $2 \mathrm{v}$.

CUNHA, G.A.P. da; CABRAL, J.R.S.; MATOS, A.P. de; CALDAS, R.C. Avaliação de genótipos de abacaxi resistentes à fusariose em Coração de Maria, Bahia. Magistra, v.19, p.219-223, 2007.

EVANGELISTA, A.W.P.; LIMA, L.A.; SILVA, A.C. da; MARTINS, C. de P. Viabilidade financeira da produção de café irrigado em regiões aptas ao cultivo não irrigado. Coffee Science, v.6, p.137-146, 2011.

FERREIRA, E.A.; SILVA, J.R.; ALMEIDA, G.V.B. de; SANTOS, W.V. Abacaxi. Informe Agropecuário, v.32, p.7-16, 2011.

LANNA, G.B.M.; REIS, R.P. Influência da mecanização da colheita na viabilidade econômico-financeira da cafeicultura no sul de Minas Gerais. Coffee Science, v.7, p.110-121, 2012.

MAIA, V.M.; ALMEIDA JÚNIOR, A.B.; MIZOBUTSI, G.P.; MIZOBUTSI, E.H.; PACHECO, D.D. Fruit and planting material production by irrigated 'Pérola' pineapple in response to planting spacing under semi-arid conditions. Acta Horticulturae, v.822, p.125-130, 2009.

OLIVEIRA, E.L. de; FARIA, M.A. de; REIS, R.P.; SILVA, M. de L.O. e. Manejo e viabilidade econômica da irrigação por gotejamento na cultura do cafeeiro acaiá considerando seis safras. Engenharia Agrícola, v.30, p.887-896, 2010.

PAIVA, R.N.; CARVALHO, C.H.S. de; MENDES, A.N.G.; ALMEIDA, S.R. de; MATIELLO, J.B.; FERREIRA, R.A. Comportamento agronômico de progênies de cafeeiro (Coffea arabica L.) em Varginha-MG. Coffee Science, v.5, p.49-58, 2010.

PEREIRA, M.A.B.; SIEBENEICHLER, S.C.; LORENÇONI, R.; ADORIAN, G.C.; SILVA, J.C. da; GARCIA, R.B.M.; PEQUENO, 
D.N.L.; SOUZA, C.M. de; BRITO, R.F.F. de. Qualidade do fruto de abacaxi comercializado pela Cooperfruto - Miranorte - TO. Revista Brasileira de Fruticultura, v.31, p.1048-1053, 2009.

PROGRAMA BRASILEIRO PARA A MODERNIZAÇÃO DA HORTICULTURA. Normas de classificação do abacaxi. São Paulo: CEAGESP, 2003. (Centro de Qualidade em Hortaliças. Documentos, 24).
SOUZA, O.P. de; TEODORO, R.E.F.; MELO, B. de; TORRES, J.R.L. Qualidade do fruto e produtividade do abacaxizeiro em diferentes densidades de plantio e lâminas de irrigação. Pesquisa Agropecuária Brasileira, v.44, p.471-477, 2009.

STEEL, R.G.D.; TORRIE, J.K. Principles and procedures of statistics: a biometrical approach. $2^{\text {nd }}$ ed. New York: McGraw-Hill, 1980. 633p.

Recebido em 26 de março de 2012 e aprovado em 29 de agosto de 2012 